\title{
INVESTIGATION OF TWO-PHASE FLOW IN SHORT HORIZONTAL MINI CHANNEL HEIGHT OF $1 \mathrm{MM}$
}

\author{
Fedor Ron'shin ${ }^{1, *}$, and Vyacheslav Cheverda ${ }^{1}$ \\ ${ }^{1}$ Kutateladze Institute of Thermophysics SB RAS, 630090 Novosibirsk, Russia
}

\begin{abstract}
The experiments with two-phase flow in the short horizontal rectangular minichannel with the height of $1 \mathrm{~mm}$ and width of $29 \mathrm{~mm}$ have been carried out using water and gas nitrogen. The five two-phase flow patterns have been recognized in the minichannel: churn, stratified, annular, bubble, and jet. These regimes are plotted on a graph and the boundaries between them determine precisely. The height of a horizontal minichannels has a significant role on boundaries between the flow regimes.
\end{abstract}

\section{Introduction}

Currently there is a rapid development of miniature heat exchangers. Studies show that the heat exchange systems with mini- and micro-dimensions turn out to be more energy efficient than macro-systems with a characteristic channel size larger than $1 \mathrm{~mm}$ [1]. With decreasing channel thick-ness the surface to volume ratio of a channel increases, which leads to high heat transfer rate in these systems. Such systems are becoming ever more in demand in the microelectronics, aerospace industry, transport and energy.

A considerable number of studies have been published in the field of two-phase flows in minichannels. An overview of publications on the two-phase flow in the channels of various configurations can be found in [2-4]. The analysis of the works shows that the structure of the two-phase flow is mainly influenced by the following parameters: geometry and dimensions of the channel [5,6], parameters of the input area [7] and fluid properties, such as viscosity and surface tension $[8,9]$. Many works describe round channels, although rectangular channels are more promising for the use in thermal stabilization systems. In rectangular channels the flow pattern is qualitatively consistent with regimes in the pipes, although the boundaries between the regimes are substantially different. There are two linear sizes, and depending on their relationship the process pattern significantly changes. Works [10-12] consider mechanisms, influencing the regimes forming in minichannels. The channel height is shown to have a significant influence on the mechanism of the two-phase flow formation.

The aim of present work is to investigate the regimes of two-phase patterns and boundaries between them in the short (length of $80 \mathrm{~mm}$ ) horizontal minichannel with the

\footnotetext{
*Corresponding author: f.ronshin@gmail.com
} 
height of $1 \mathrm{~mm}$ and width of $29 \mathrm{~mm}$ using the modern techniques and to compare them with the channel with cross-section of $0.3 \times 30 \mathrm{~mm}^{2}$.

\section{Experimental results}

The regimes of two-phase flow in the minichannel with cross-section of $1 \times 29 \mathrm{~mm}$ have been experimentally studied using fluorescence technique (this technique is described in [13]) and a digital video camera. The flow regime map has been created for the investigated channel (fig. 1). The superficial gas $U_{S G}$ and liquid $U_{S L}$ velocities, determined as the volumetric gas or liquid flow rate divided by the channel cross-section, are used as the coordinates in the figure. The following two-phase flow patterns have been detected in the channel: churn, stratified, annular, bubble, and jet.

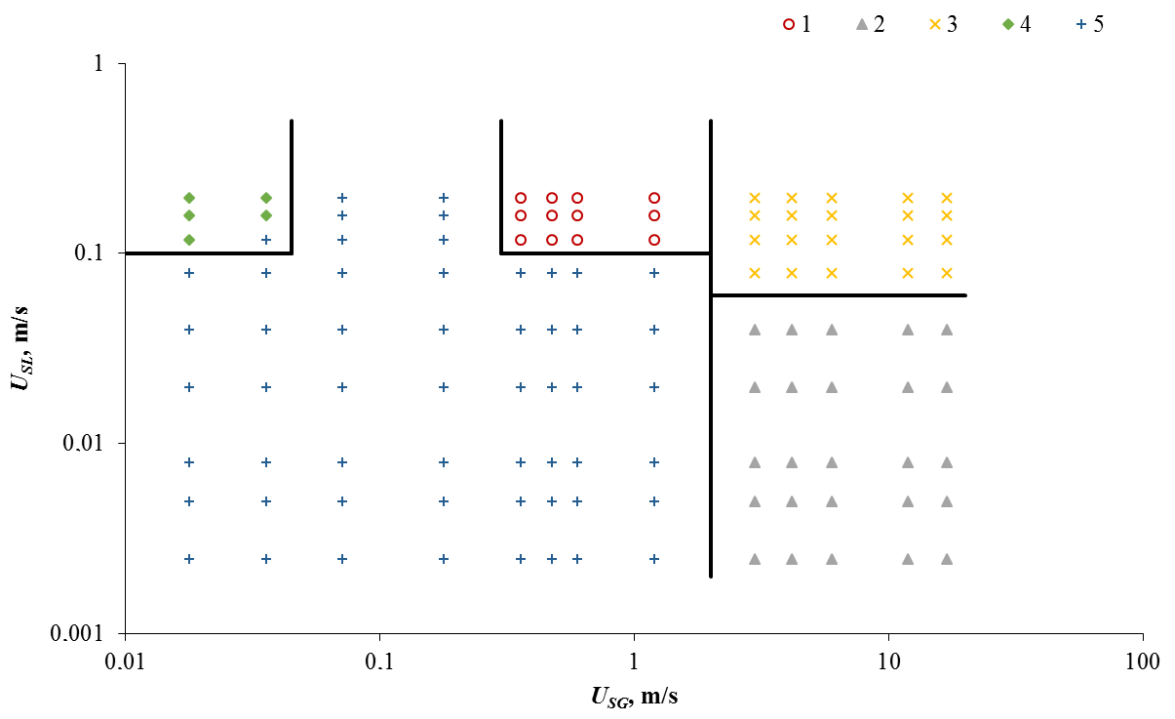

Fig. 1. Map of two-phase flow in the minichannel with cross section of $1 \times 29 \mathrm{~mm}^{2}$. Flow regimes: (1) churn; (2) stratified; (3) annular; (4) bubble; (5) jet.

In the range of low superficial velocities of liquid, gas moves in the central part of the channel, while the bulk of liquid moves along its periphery along lateral walls. Disturbances on the surface of the liquid are not observed. The stationary jet regime is observed at low superficial velocities of liquid and gas, when the gas flow occupies no more than a half of the channel cross section. The jet flow pattern is shown in figure $2 \mathrm{c}$ $\left(U_{S L}=0.039 \mathrm{~m} / \mathrm{s}, U_{S G}=0.178 \mathrm{~m} / \mathrm{s}\right)$. The liquid film moves along the bottom wall of the channel, the liquid completely fills the lateral sides of the channel. By increasing superficial liquid velocity, the liquid pulsations occurs in the lateral parts of the channel. By increasing the superficial gas velocity, when the gas begin to occupy larger volume than the liquid, the transition to the stratified flow regime takes place. In this regime, part of the liquid moves along the bottom channel wall in the form of a film together with the gas stream. The liquid fills the lateral sides of the channel. The stratified flow pattern is shown in figure $2 \mathrm{a}$ $\left(U_{S L}=0.02 \mathrm{~m} / \mathrm{s}, U_{S G}=16.95 \mathrm{~m} / \mathrm{s}\right)$. In this case liquid film moves along the bottom wall of the minichannel and a liquid pulsation can be observed in the lateral parts of the channel. By increasing superficial liquid velocity, liquid emissions occur from the lateral sides of the channel and one forms the film on the upper wall of the channel. The transition to the annular flow regime takes place. The film in such flow regime moves along the channel together with the gas stream at the top and bottom walls of the channel. In this regime gas 
together with droplets forms the core of the flow in the center of microchannel. Gas occupies the most part of the microchannel cross-section and near with the lateral walls, the pulsating motion of liquid is observed. the annular flow pattern is sown in figure $2 \mathrm{~b}$ $\left(U_{S L}=0.195 \mathrm{~m} / \mathrm{s}, U_{S G}=16.95 \mathrm{~m} / \mathrm{s}\right)$. In this regime, one can see a liquid film moving on the window. The bubble flow regime is observed at high superficial liquid velocities and low superficial gas velocities. In such regime, liquid comprising many small gas bubbles moves along the minichannel. The size and amount of bubbles vary depending on liquid and gas flow rates, but the sizes of the bubble are always much smaller than the channel width. The bubble frequency increases with increasing superficial liquid and gas velocities. The breaks in the bridges begin to appear with increasing the superficial gas velocity, the transition to the churn flow regime takes place, figure $2 \mathrm{~d}$. This flow pattern is discussed in more details in [14]. The main characteristic of this flow regime is the existence of continuous and broken liquid bridges. The transition from the jet regime to the churn regime occurs with an increase of superficial velocity of the liquid and the transition is accompanied by the appearance of continuous liquid bridges, which are stable and the number of which in the minichannel was more than one. In the figure $2 \mathrm{~d}$ one can see the broken bridges, which is not observed in the jet and stratified flows. The transition from the bubbly (continuous filled liquid bridges) to the churn regime was accompanied by the appearance of breaks in the bridges. Upon the transition to the annular flow regime, the continuous filled liquid bridges disappear; upon the passage to the bubbly regime, they become stable.
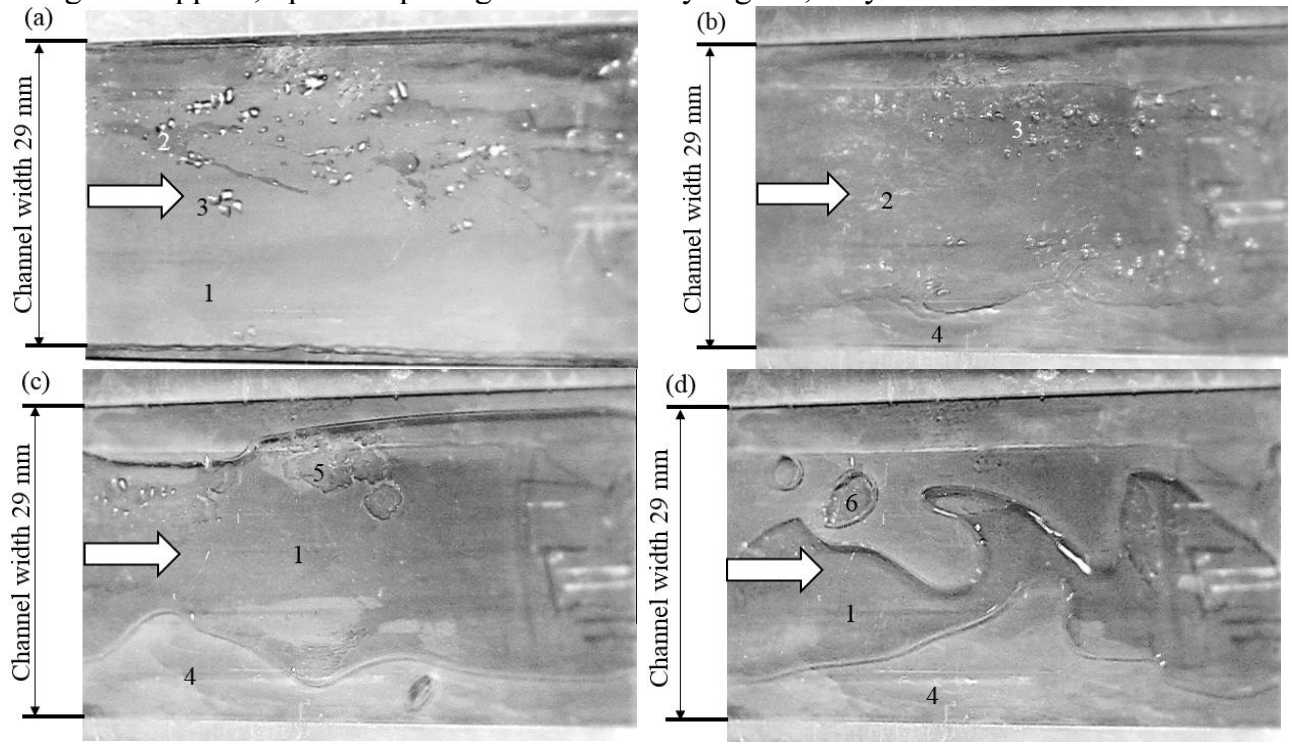

Fig. 2. Typical photographs of the regimes: (a) Stratified flow regime at $U_{S L}=0.02 \mathrm{~m} / \mathrm{s}, U_{S G}=16.95$ $\mathrm{m} / \mathrm{s}$; (b) Annular flow regime at $U_{S L}=0.195 \mathrm{~m} / \mathrm{s}, U_{S G}=16.95 \mathrm{~m} / \mathrm{s}$; (c) Jet flow regime at $U_{S L}=0.039$ $\mathrm{m} / \mathrm{s}, U_{S G}=0.178 \mathrm{~m} / \mathrm{s}$; (d) Churn flow regime at $U_{S L}=0.195 \mathrm{~m} / \mathrm{s}, U_{S G}=0.6 \mathrm{~m} / \mathrm{s} ; 1-$ liquid film on the bottom channel wall, 2 - liquid film on the upper channel wall, 3 - liquid drops, 4 - the channel regions fully filled with liquid, 5 - unwetted zone on the bottom channel wall, 6 - gas bubbles. 


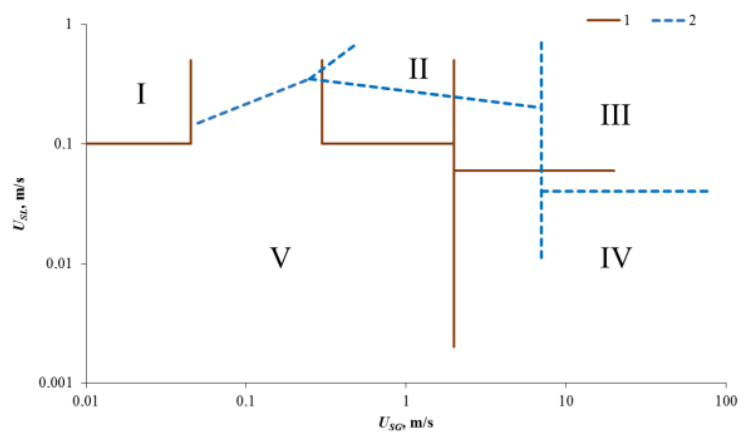

Fig. 3. Influence of the channel highs on the flow patterns for the channels with sections of $1 \times 29 \mathrm{~mm}^{2}$ (1) and $0.3 \times 30 \mathrm{~mm}^{2}$ (2). Flow patterns: (I) bubble, (II) churn, (III) annular, (IV) stratified, and (V) jet.

The comparison between two flow pattern map for the microchannels with sizes $1 \times 29 \mathrm{~mm}^{2}$ and $0.3 \times 30 \mathrm{~mm}^{2}$ is demonstrated in Figure 3. It is seen that with a decrease in the channel height the boundaries between the jet and the stratified modes, and the jet and the annular modes shift towards higher reduced velocities of the gas, significantly increasing the area of the jet mode. The boundary between the churn and the jet regimes is shifted towards higher reduced velocities of the fluid. The area of the bubble regime is shifted towards higher reduced velocities of the gas and liquid. The boundary between stratified and annular regimes does not change significantly.

\section{Acknowledgments}

We gratefully acknowledge the support from the Ministry of Education and Science of Russia (No. 14.604.21.0053 Project identifier RFMEFI60414X0053).

\section{References}

1. V.V. Zamashchikov, A.A. Korzhavin, E.A. Chinnov, Combust. Explos. Shock Waves 50, 381 (2014)

2. N. Shao, A. Gavriilidis, P. Angeli, Chemical Engineering Science 64, 2749 (2009)

3. E.A. Chinnov, O.A. Kabov, High Temp. 44, 773 (2006)

4. E.V. Rebrov, Theor. Found. Chem. Eng. 44, 355 (2010)

5. J.W. Coleman, S. Garimella, Int. J. Heat Mass Transfer 42, 2869 (1999)

6. T.S. Zhao, Q.C. Bi, Int. J. Multiphase Flow 27, 765 (2001)

7. V. Haverkamp, V. Hessel, H. Löwe et al., Chem. Eng. Technol. 29, 1015 (2006)

8. S. Waelchli, P.R. von Rohr, Int. J. Multiphase Flow 32, 791 (2006)

9. R. Pohorecki, P. Sobieszuk, K. Kula, W. Moniuk, M. Zielinski, P. Cyganski, P.Gawinski, Chem. Engng J. 135, S185 (2008)

10. O.A. Kabov, E.A. Chinnov, V.Cheverda, Microgravity sci. technol. XIX-3/4, 44 (2007)

11. E.A. Chinnov, V.V. Guzanov, O.A. Kabov, Tech. Phys. Lett. 35, 653 (2009)

12. E.A. Chinnov, F. Ron'shin, O.A. Kabov, Int. J. Multiphase Flow 80, 57 (2016)

13. E.A. Chinnov, J. Heat Transfer 138, 7 (2016)

14. E.A. Chinnov, F.V. Ron'shin, V.V. Guzanov, D.M. Markovich, O.A. Kabov, High Temp. 52, 681 (2014)

15. E.A. Chinnov, F.V. Ron'shin, O.A. Kabov, Tech. Phys. Lett. 41, 817 (2015) 